\title{
The roles and uses of design principles for developing the trialogical approach on learning
}

\author{
Sami Paavola ${ }^{a *}$, Minna Lakkala ${ }^{\mathrm{a}}$, Hanni Muukkonen ${ }^{\mathrm{b}}$, Kari Kosonen ${ }^{\mathrm{a}}$ and \\ Klas Karlgren ${ }^{\mathrm{c}}$ \\ ${ }^{a}$ Institute of Behavioural Sciences, University of Helsinki, Helsinki, Finland; ${ }^{b}$ Department of \\ Teacher Education, University of Helsinki, Helsinki, Finland; ' $D$ Department of Learning, \\ Informatics, Management and Ethics \& KI-SÖS, Karolinska Institutet, Stockholm, Sweden
}

(Received 7 February 2011; final version received 12 September 2011)

In the present paper, the development and use of a specific set of pedagogical design principles in a large research and development project are analysed. The project (the Knowledge Practices Laboratory) developed technology and a pedagogical approach to support certain kinds of collaborative knowledge creation practices related to the 'trialogical' approach on learning. The design principles for trialogical learning are examined from three main developmental perspectives that were emphasised in the project: theory, pedagogy, and technology. As expected, the design principles had many different roles but not as straightforward or overarching as was planned. In their outer form they were more resistant to big changes than was expected but they were elaborated and specified during the process. How theories change in design-based research is discussed on the basis of the analysis. Design principles are usually seen as providing a bridge between theory and practice, but the present case showed that also complementary, more concrete frameworks are needed for bridging theory to practical pedagogical or technical design solutions.

Keywords: design principles; design-based research; educational theory; trialogical learning; knowledge creation metaphor

\section{Introduction}

The nature of design-based research awakes constant interest and dispute (for example, Design-Based Research Collective 2003; Engeström 2008) and it has become a more popular approach also in educational research. Design solutions are investigated in complex real-world contexts, and practitioners and researchers work together. Specific to design-based research is that research, theory and practice are intertwined in the studies (Edelson 2002). There are different conceptions on the role of theory in design-based research but nowadays it is often maintained that the aim is to iteratively develop also theories (Bell, Hoadley, and Linn 2004; DesignBased Research Collective 2003).

One emerging solution for designing complex learning settings has been to define generic design principles that explicate central features of one's pedagogical approach to guide the designer (Kali 2006). Design principles are supposed to

*Corresponding author. Email: sami.paavola@helsinki.fi 
emerge from previous research and to inform future design activities (Bell, Hoadley, and Linn 2004). They are seen to operate as a bridge between theories of learning and pragmatic aspects of learning. The origin of design principles can be either theoretically, empirically or practically informed (for example, Scardamalia 2002; Kaptelinin, Nardi, and Macaulay 1999; Kali, Levin-Peled, and Dori 2009; McKenney, Nieveen, and Van den Akker 2006).

In the present paper we analyse the roles of a specific set of pedagogical design principles in a large research and development project. This project developed technology and a pedagogical approach - called trialogical learning - to support collaborative knowledge practices typical for knowledge work. A set of design principles were developed to characterise main features of trialogical learning in order to promote them theoretically, in pedagogical practices, and in technology development and design. We will first describe the project in question, and then analyse the basis and various main uses of these design principles in the project. Finally, we will discuss the role of these kinds of theoretically motivated design principles in the analysed research and development endeavour, and discuss lessons learnt concerning the nature of design-based research in general.

\section{The investigated project}

The examined project was a five-year long (February 2006-January 2011) European Union-funded project called the Knowledge Practices Laboratory (KP-Lab). ${ }^{1}$ The project was an integrated project with over 20 partners from 14 countries.

The project had a background in the ideas concerning the knowledge creation metaphor of learning (KCM) (Paavola, Lipponen, and Hakkarainen 2004). The $\mathrm{KCM}$ is a sequel to Anna Sfard's famous distinction between the acquisition and the participation metaphors of learning, emphasising either individuals and conceptual knowledge, or social processes and interaction (Sfard 1998). KCM builds on the claim that in order to understand modern knowledge work and related theories of collaborative learning and human cognition, the two metaphors are not enough (Paavola and Hakkarainen 2005; see also Engeström 1987; Bereiter 2002). There are various conceptions regarding requirements of modern knowledge work but theories adhering to $\mathrm{KCM}$ highlight competencies required in producing knowledge and various things, and solving problems together. These competences are in an increasing extent related to the use of digital technology in advancing various knowledge objects by communities' collaborative efforts and resources (Bereiter 2002; Hakkarainen et al. 2004). As a rule, the objects addressed in knowledge work are open and multi-faceted in their nature (for instance, new computer softwares, working concepts, commodities) and are developed for subsequent use. Consequently digital technology should in a flexible way support their modelling, sketching, testing and finalisation as well as the interactions between the knowledge workers involved.

An explicit goal of the KP-Lab project was to develop and investigate the theoretical foundations, pedagogical practices and methods as well as tools that support collaborative knowledge creation processes both in educational and working contexts. Co-design of tools by pedagogical, theoretical and technological partners and ideas was emphasised.

The KP-Lab project included research in various settings especially on higher education, but also in the areas of teacher training and workplace 
settings. One focus was on higher education courses where students develop concrete, usable solutions, products or applications that address some specific problems provided by outside organisations as customers. The aim of such courses is to learn project work and knowledge practices applied by real professionals in working life. Collaboration between educational institutions and companies is more common in the universities of applied sciences or polytechnics that orient more towards applied research, learning of professional practices and collaboration with professional organisations. However, similar practices are increasingly implemented also in science universities where research and teaching have traditionally emphasised theoretical issues and basic research without direct contacts to application fields.

The project has developed a general pedagogical approach called trialogical learning representing the knowledge creation metaphor of learning. In trialogical learning (see Figure 1), the focus is not just on learners (emphasised in the acquisition metaphor of learning) nor just on social processes or dialogues (emphasised in the participation metaphor of learning), but also on a third element; that is, on jointly developed 'objects' (knowledge artefacts, processes or practices) meant for some later use (Paavola and Hakkarainen 2005, 2009). The trialogical learning has clear influences from the knowledge-building approach (Bereiter 2002) with a focus on knowledge artefacts, but also from activity theory (see especially Engeström 1987) by emphasising 'objects' and object-oriented activity more generally. It is in line also with other approaches highlighting the role of knowledge objects and knowledge practices (see especially Knorr-Cetina 2001).

In the KP-Lab project, technology was developed through several phases in collaboration with pedagogical and technological partners. The project developed various tools for different functions of knowledge work; for supporting meetings (a technology called Map-It), an event sampling methodology using mobile phones (CASS-Query), an annotation tool for video data (SMAT), and a tool supporting developmental work research (ASDT). A central tool being developed

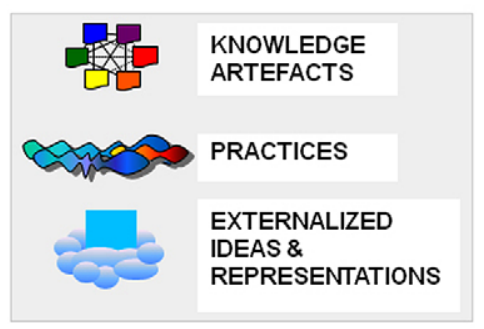

\section{"AUTHENTIC" USE OF THE OBJECTS}

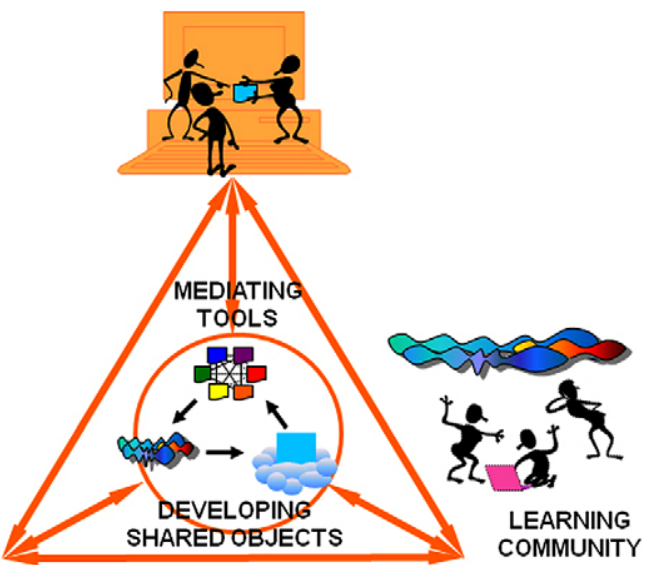

Figure 1. An illustration of the trialogical approach on learning presenting its basic elements.

Source: Paavola and Hakkarainen (2009). 
was, however, a virtual environment called the Knowledge Practices Environment (KPE) (see, for example, Lakkala et al. 2009). KPE is a web-based application for user groups to create 'Shared spaces'. It provides specific affordances for developing and organising shared knowledge artefacts (e.g. files, notes, weblinks) as well as for planning, organising and reflecting on related tasks and user networks. It includes a set of basic, integrated tools and functionalities with real-time and history based awareness, wiki, note editor, commenting, chat, semantic tagging and semantic search among others. KPE enables users to organise knowledge artefacts and tasks (represented by graphical icons) through flexible visual representations (with linking and tagging), and from different perspectives or 'views'. The central view is the Content view that allows free visual arrangement and linking of its content (see Figure 2). Other main views are the Process view, and the Community view. Various tools and functionalities are highly integrated to enable versatile and flexible connection, organisation and reflection of all information related to the knowledge artefacts, processes, and people concerned.

The KP-Lab project was a long project with many design challenges. It included research partners, and pedagogical and technology developers from a variety of cultural, disciplinary and theoretical backgrounds. Annual, often very critical, project reviews put a lot of pressure on developing an integrated research strategy, pedagogical models and novel tools. Both the research cases investigated and the tool development were refocused a couple of times during the project.

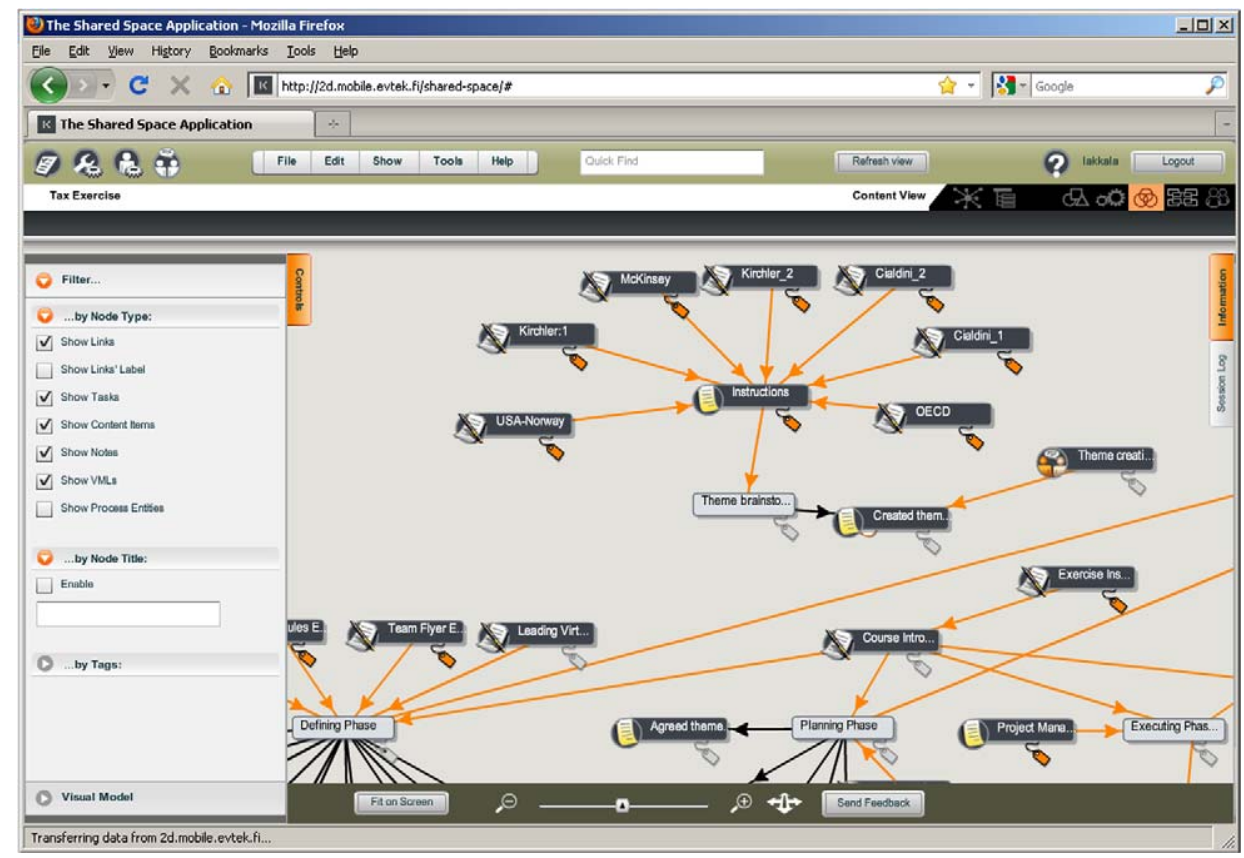

Figure 2. An example of the Content view in KPE.

Note: The dark-shaded items are content items, such as up-loadable files, links to the Internet, and notes; the orange and black arrows are links added by the user; the lightshaded items are tasks defined by the user. 


\section{The use of design principles for trialogical learning in the project}

The design principles served multiple purposes in the investigated project. We examine the principles from three main perspectives:

(1) Theory development. Initially, the design principles had a strong theory-driven origin in the project. However, they did not represent just one existing theoretical outlook but had a broader background.

(2) Development of pedagogical scenarios, models, and research. This perspective concerns how the design principles were used for focusing the cases and research, and for developing pedagogical practices.

(3) Technology development concerns how the design principles guided technology development as well as co-design between technology experts, educational researchers, and user feedback.

The iterations of and the interplay between theoretical considerations, pedagogical practices, and tool development were emphasised from the start of the KP-Lab project. Differences in the approaches to use design principles reflect diverging research traditions and perspectives underlying the research in social sciences versus design sciences, both of which were represented in the project. Moreover, a characteristic of research in design sciences is that it involves several cycles, thereby leading to multiple roles of the design principles depending on the phase of the process (Hevner 2007).

\section{Theory development}

The design principles for trialogical learning had a background in previous theoretical work concerning the knowledge-creation metaphor of learning, such as the knowledge-building approach (Bereiter 2002), expansive learning and activity theory (Engeström 1987), and organisational knowledge creation by Nonaka and Takeuchi (1995). These approaches appear quite different with each other but there are also some underlying similarities. These similarities were listed as seven common features by Paavola, Lipponen, and Hakkarainen (2004, 562):

(1) The pursuit of newness.

(2) Mediating elements to avoid Cartesian dualisms.

(3) Viewing knowledge creation as a social process.

(4) Emphasis on the role of individual subjects in knowledge creation.

(5) Going beyond propositional and conceptual knowledge.

(6) Recognising conceptualisations and conceptual artefacts as important.

(7) Interaction around and through shared objects.

These features provided an evident basis for later development of the design principles in the KP-Lab project. The commonalities of these approaches have been discussed also in other papers, and the framework developed especially within the context of collaborative learning on the basis of these comparisons was called the trialogical approach (Paavola and Hakkarainen 2005).

The knowledge creation metaphor seemed to be a good background for a large project like the KP-Lab. It provided an 'umbrella' that left room for somewhat deviating theoretical orientations (almost unavoidable in a large project) but with a 
common aim of developing the knowledge creation approach further. Many research partners in the project had previous experience of developing learning technology and collaborative learning environments, and were interested in activity theory. Therefore, there was enough common ground for collaboration.

The general features and characteristics of trialogical learning were dealt with in the kick-off meeting of the KP-Lab project. The scientific coordinator of the project made also a paper listing first 12 and then 31 characteristics of trialogical learning and technology design (Hakkarainen 2006). These characteristics were explicitly linked to knowledge building principles by Scardamalia (2002), but were influenced also by the activity theoretical research. Additional sources for defining the design principles were previous experiences of the KP-Lab partners in developing learning technology, and an explicit goal of the project to develop such courses where students would be in a close contact with real customers solving complex problems.

On the basis of these various sources, the actual Design Principles (DPs) for trialogical learning were then formulated by the project researchers responsible for defining theoretical foundations. The goal was to make an initial, and a relatively short, list of DPs, which would cover the central characteristics of trialogical learning. These DPs were not defined with strict pre-defined starting points or goals because they were meant to support "an open ended, continually evolving and unpredictable process of transforming knowledge practices" (KP-Lab 2006a). They were meant to be open for revisions and to be continuously checked during the project. The initial list of DPs was:

(1) Organise trialogical activity around shared objects.

(2) Interaction between personal and social levels of activity.

(3) Flexible tool mediation for trialogical activity.

(4) Fostering long-term processes of knowledge advancement.

(5) Development through transformation and reflection.

(6) Eliciting (individual and collective) agency.

(7) Cross fertilisation of knowledge practices.

According to the plan, DPs were meant to be used in a theoretical work (to develop them further), to guide especially the variety of educational studies, and also to inform the development of technology and its usability evaluation. These DPs were not meant to be the only conceptual tool to guide theoretical, pedagogical and technological development. For example, pedagogical scenarios and theoretical glossaries were also created.

What has been notable from the theoretical perspective is that the basic formulations of these DPs have not changed much. This has been the case despite the original intent of making revisions to them (e.g. based on new research results where DPs were revisited). The biggest change was that two DPs - (2) and (6) above were merged into one. This was done when they were seen to be quite close to each other, and also because the sixth one was considered to be somewhat hard to operationalise in pedagogical practices. The order of the DPs was changed without any deep reasons but for the sake of presentations. Also some small changes in specifications and wording have been made. Otherwise the list of design principles at the end of the project was almost the same as at the start (for example, KP-Lab 2010). The later references of DPs in this paper are related to this set of design principles for trialogical learning: 
(DP1) Organising activities around shared 'objects'.

(DP2) Supporting integration of personal and collective agency and work through developing shared objects.

(DP3) Emphasising development and creativity in working on shared objects through transformations and reflection.

(DP4) Fostering long-term processes of knowledge advancement with shared objects (artefacts and practices).

(DP5) Promoting cross-fertilisation of various knowledge practices and artefacts across communities and institutions.

(DP6) Providing flexible tools for developing artefacts and practices.

Although there were only small changes in the outer format of DPs, it does not mean that they were not reconsidered also from the theoretical perspective. The first DP ('Organising activities around shared "objects"') is the central one and various meanings of the term 'object' aroused a lot of discussion in the project. These discussions were related to the use of the term 'object' more generally in educational research (see, for example, Kaptelinin and Miettinen 2005; Muukkonen-van der Meer 2011). A shared object was considered either as a shared 'topic' (close to objective) or as a shared, concrete knowledge artefact (document, plan, model, etc.), or both. It was also discussed, in which sense shared objects mean versioning of the same knowledge artefact or (which is typical in a project work) working with several, different knowledge artefacts. In addition, all along the project the partners discussed whether shared objects are only knowledge artefacts or can they also be practices, or knowledge processes. In all these respects, there were somewhat deviating interpretations by different partners which kept these discussions ongoing.

Also DP4 on fostering 'long-term' processes raised multiple interpretations. The idea was that knowledge-creation processes and practice transformations need time. This can be interpreted in many ways, meaning, for example, several iterations needed within one course, changes across courses, or longer-term cultural changes taking several years. Also DP5 on 'cross-fertilisation' awoke various interpretations. Cross-fertilisation refers to interaction between different organisations, for example, by solving complex problems and producing products for purposes outside educational institutions, or having collaboration with students and external experts. This collaboration can then have various forms and intensity levels, which required specification.

\section{Pedagogical use of the design principles for trialogical learning}

\section{A heuristic framework for pedagogical settings}

From the start, the KP-Lab project contained a variety of pedagogical and technological starting points and aims. Pedagogical scenarios were used to provide a concrete starting point for pedagogical development. Pedagogical scenarios were built on the basis of those educational practices and institutional contexts that different pedagogical partners saw relevant and a potential baseline for further development. The project report (KP-Lab 2006b) listed 23 pedagogical scenarios collected from eight partners. These scenarios included information on: shared object; intention/ purpose; institutional contexts; participants; activities; process structures; and challenges within the scenario. These scenarios were needed also for starting to concretise technological requirements. 
While the KP-Lab design principles are grounded in theory and aim to provide general guidelines, the pedagogical scenarios are closely bound to current educational practices and are situated in an organisational context. (KP-Lab 2006b, 3)

The aim of the pedagogical scenarios was to operationalise and concretise the design principles, but it became obvious that there existed tensions and discrepancies between scenarios and design principles. Pedagogical scenarios were oriented towards existing pedagogical practices, design principles towards future theoretical aims. These differences were interpreted to reflect inherent tensions between theory and current practices, but also to provide means for finding potential developmental paths in the project.

The trialogical DPs were quite general and meant for providing broad guidelines rather than strict criteria for pedagogical design. One challenge caused by this broadness was that they could be interpreted in multiple ways. Coupled with normal challenges of this kind of a project of finding pedagogical settings to be investigated, this broadness created some pedagogical scenarios that were quite loosely connected to the trialogical DPs. When pedagogical scenarios were constructed and evaluated, DPs and pedagogical scenarios were vividly discussed and specified further.

The trialogical DPs were used also later on in the project to give a framework and guidelines for evaluating pedagogical settings and courses. To answer a call for clarifications on the theoretical implications of various research cases by a project review, a taxonomy was constructed based on the reformulated design principles (KP-Lab 2009b). This framework defined three qualitatively different levels for each DP, representing the three metaphors of learning: acquisition-type practices, participation-type practices, and knowledge-creation-type practices (on three metaphors - see above). On the basis of this framework, the level of actualising the trialogical DPs in the investigated courses was investigated and potential development directions for the courses were specified. The trialogical approach and its design principles were meant to be interpreted as 'vehicles of innovation'; that is, providing ideas for changing existing practices. DPs were then meant to be interpreted somewhat differently depending on the context.

\section{An example of using DPs in an intervention}

Here an example of an interventionist use of the trialogical DPs in the KP-Lab studies is described. The case focused on specific courses arranged at a hospital in Stockholm for training in inter-professional resuscitation teams. The overarching objective was to support medical teams in improving their coordination, leadership, teamwork, communication, and analysis practices in order to contribute to patient safety. The courses are intensive one-day courses starting with lectures and simulations followed by debriefing and feedback sessions. In the simulations, the course participants work in teams to practice the solving of complex, authentic cases: the medical teams provide intensive care to newborns (a small manikin) arriving from the delivery room. Immediately after each simulation, the teams are debriefed and video-recordings of the simulations are analysed together with the instructors.

The design principles were an inspiration in addressing a number of the challenges in the case. For example, the lack of an obvious 'shared object' (DP1) was one problem: the course participants typically did not have a shared understanding 
of the teamwork events nor did they engage in the intended knowledge practices. After several rounds of modifying the course it became more and more clear that the analysis of practices during the debriefings had a key role in the participants' development.

Not all course participants were as active in analysing during debriefings and the teams were not very skilled at utilising the entire team's observations and viewpoints. Some individuals dominated while others were not heard. Inspired by the design principle emphasising support for interaction between personal and social levels (DP2), different combinations of individual and collaborative tasks were tested.

With these kinds of uses of design principles as a starting point, a conceptual model was designed for use during the courses (Karlgren et al. 2007). It was used for highlighting the issues during debriefings as well as for scoring the performance of the teams. Moreover, another aspect of the design work concerned the use of tools that were introduced: decisions needed to be taken about, for example, when to use them (e.g. directly after each simulation or less frequently) and how (individually or collaboratively).

There is not, however, a simple relationship between design principles and the resulting design solutions - these could have taken many different alternative forms. In general, design principles do not explain why or when they should be applied and have therefore come under criticism on several counts (Borchers 2000; Mahemoff and Johnston 1998): for their difficulty of interpretation, for being too simplistic, for requiring sophisticated interpretation, for risks of neglecting or misinterpreting advice and guidelines, and so forth.

However, the use of the DPs for trialogical learning was not a matter of simple application or implementation of a set of principles. The theoretical basis is novel and the use of the principles was of an exploratory kind. As an attempt to capture pedagogical practices that worked well in this particular case and to let these feed back to the design principles, educational design patterns were created. These were used as tools for documenting those pedagogical practices that appeared fruitful and which might be useful in other future cases by linking the 'pedagogical solution' that is, a certain planned activity or practice - to the problems that these addressed in the concrete case on the one hand, and to the design principles on the other hand. A design pattern is a three-part rule, which expresses a relation between a certain context, a problem, and a solution (Alexander 1979). Design patterns have the advantage of clearly connecting concrete solutions to concrete problems and to indicate which contexts they work in. The pattern format thus provided a structured way of documenting good examples in the case that could then be connected to the more abstract ideas of the design principles, thereby concretising the meaning of the principles in this type of a context.

\section{Design principles as a reporting and analysis framework}

One prominent function of the design principles for trialogical learning in the KP$\mathrm{Lab}$ project was to provide a framework for reporting results from research cases. This function was important especially at the early stages of the project (see KPLab 2007a, KP-Lab 2007b). The DPs helped making comparisons of interpretations and findings across cases. A common framework was needed for fitting different research traditions and different interpretations of the aims of the project together. 
Educational research in the KP-Lab project was divided in three main contexts, higher education, teacher training, and workplace studies. DPs were used for reporting especially on higher education courses. Concretely this meant that the results were presented in relation to each design principle. At the same time, the design principles were elaborated further by commenting on them in the discussion part of the report.

Later on, DPs were not so systematically used as a framework for reporting the results across cases. One reason for this was that other design conceptualisations especially concerning technology were developed that were only indirectly linked to the DPs (see below). Also a more elaborated data analysis framework was developed that used a more data-driven approach compared with theoretically oriented DPs. But this does not mean that the DPs were not used at all anymore for framing the research and its results. In the later period of the project, when pedagogical and theoretical implications and concrete recommendations from research cases were collected, the DPs were used again as a useful framework (KP-Lab 2010).

The DPs were used also somewhat during data analysis. For instance, two course set-ups from higher education were analysed in detail through the design principles for trialogical learning to explore their applicability in evaluating pedagogical practices (see Lakkala et al. 2010). The DPs helped account for the characteristics of the design of the two, in themselves different courses through unifying terms, and enabled the explication of some shortcomings and suggestions for improvements concerning the implementation of trialogical learning in the course designs. This analysis, again, lead to discussions on the interpretations of DPs, and some specifications were suggested.

\section{Design principles and technology development}

The original aim was to use the DPs as broad guidelines for the technological development. This influence, however, turned out to be more indirect for several reasons. It was realised early on in the project that the trialogical DPs were too abstract for guiding concrete co-design and technological development.

Requirements for technological development were collected, first of all, by technological partners who were able to provide requirements for basic functionalities needed. This was supplemented with requirements that were extracted from various pedagogical scenarios provided by pedagogical partners. The created collection of requirements was not connected only to DPs or to theoretical emphases. The long list of requirements was grouped by using types of mediation (KP-Lab 2009a). The types of mediation were adapted and modified from the work of Pierre Rabardel and his colleagues (Rabardel and Bourmaud 2003; see Hakkarainen 2008). Epistemic mediation related to creating and working with epistemic artefacts, pragmatic mediation related to organising knowledge-creation projects and processes, collaborative mediation concerning building and managing networked communities required for carrying out knowledge-advancement efforts, and reflective mediation in terms of making visible, reflecting on, and transforming knowledge practices.

The four types of mediation are interlinked with the DPs. For example, epistemic mediation is emphasised in the DP1 (work on knowledge artefacts as shared objects). There was no direct mapping between the design principles and the types of mediation but they were considered to complement each other. The types of mediation provided a kind of an alternative framework oriented towards the role of 
technology in trialogical practices. The DPs, on the other hand, were more oriented towards designing entire educational set-ups.

Several functionalities of KPE are quite directly linked to theoretical ideas of trialogical learning, and to the DPs (especially the DP1). One of the core ideas of $\mathrm{KPE}$ is that knowledge artefacts are brought to the centre of the activities. In the Content view (see Figure 2), knowledge artefacts can be grouped, organised and reorganised easily both visually and conceptually. Different perspectives and views can be taken to work on these 'objects'. A specific Note editor was constructed in order to have a tool for making short texts quickly and easily to be versioned collaboratively if needed, and to be added wherever in the shared space in question. On the other hand, tools allowing discussion between participants are implemented as 'object-bound' functionalities. For instance, all objects (content or task items, etc.) in a Content view can directly be attached by (threaded) comments. Similarly, object-bound chat enables synchronous interchange attached directly into the object at hand. Chat logs are saved and linked to the targeted items, thereby keeping them attached for possible re-use. In addition, the Alternative Process view gives more flexible means for organising and reorganising tasks and processes both visually and conceptually than the chronologically ordered Process view.

\section{Discussion}

The DPs for trialogical learning had different roles and functions in the described project. In summary, the most important of these functions were to provide:

- means for explicating and communicating elements that were considered central in trialogical learning;

- a basis for discussions on central concepts and phenomena of trialogical learning, both theoretically (e.g. how to interpret 'shared object') and pragmatically (e.g. what it means to foster long-term processes of knowledge advancement);

- criteria for selecting and focusing the research cases;

- suggestions for developing existing practices;

- a framework for reporting results and findings across research cases; and

- ideas on tool functionalities supporting trialogical learning.

The trialogical DPs operated then as "loose concepts", or "boundary concepts" (see Löwy 1992) for the co-design efforts, providing an anchor for a very large project aiming at combining theoretical ideas, pedagogical practices, and technology development.

Still it can be maintained that the use of the DPs was not as straightforward or overarching as was planned in the beginning of the project. Other conceptualisations were constructed, especially for describing the technology developed in the project. Similarly, pedagogical scenarios and models provided supplementary conceptualisations concerning pedagogical practices. DPs did not lose their role in explicating the central elements of trialogical learning but they needed to be interpreted along these other conceptualisations.

The most serious criticisms of these DPs were typical criticisms directed towards design principles in general. They were seen as: somewhat ambiguous and in need of interpretation; and quite general, not giving concrete guidelines for pedagogical or technological development. The DPs had a strong theoretical background 
and were aimed at giving guidelines for a variety of cases and contexts rather than providing concrete guidelines for specific settings. The interventionist case from medical education above is a good example of this. The DPs did not specify in any detail what to do but they gave heuristic guidance about what to emphasise in the interventions. In a sense their meaning had to be reinvented for this specific setting because the design principles for trialogical learning had not been 'applied' or 'implemented' in similar settings before. At the same time, the resulting solutions provided input to the meaning of the design principles by anchoring them to a concrete case. Design patterns were then used as a tool for capturing concrete solutions and linking DPs to concrete problems.

Maybe the biggest surprise with the use of these DPs has been that in their outer form they were more resistant to any big changes than was expected. They were revisited and elaborated several times during the project. But the main formulations did not change as much as was expected at the start. This does not mean that they were not changed at all during the project. Their meaning was specified on the basis of theoretical discussions, findings from research cases, and technology development.

\section{Conclusions}

The design principles are viewed as providing a bridge between theory and practice. They "speak to the pragmatic aspects of practice while also informing theories of learning" (Bell, Hoadley, and Linn 2004, 81). Our case on the development and use of design principles in a large research and development project shows this kind of a dual role but not as directly as might be expected.

It is often remarked in design-based research literature that theories should be developed along with practices (for example, Edelson 2002; Gravemeijer and Cobb 2006). We agree with this. Our case shows, however, that these kinds of conceptualisations can be more resistant to change than expected. It can, of course, be maintained that in our case there were some specific reasons for this resistance. The design principles for trialogical learning had a strong background in previous theories that might have affected their relative stability. It could also be maintained that we could or should have changed the DPs more on the basis of our findings and results. This might be true. But on the basis of our other experiences of using similar conceptualisations in design-based research, it seems quite common that the conceptualisations themselves are not necessarily changing much. Interpretations are changed, explanations become more focused, and more specific ways of applying them are identified.

It then seems both practical applications and theoretical development require conscious development of its own and cannot be taken for granted as a result of the design-based research.

\section{Acknowledgements}

The article is developed within the framework of KP-Lab Integrated Project, which is sponsored under the 6th EU Framework Programme for Research and Development.

\section{Note}

1. See http://www.kp-lab.org; http://www.knowledgepractices.info. 


\section{References}

Alexander, C. 1979. The timeless way of building. New York: Oxford University Press.

Bell, P., C.M. Hoadley, and M.C. Linn. 2004. Design-based research in education. In Internet environments for science education, ed. M.C. Linn, E.A. Davis, and P. Bell, 73-85. Mahwah, NJ: Erlbaum.

Bereiter, C. 2002. Education and mind in the knowledge age. Mahwah, NJ: Erlbaum.

Borchers, J.O. 2000. Interaction design patterns: Twelve theses. Paper presented at the CHI2000 Patterns Workshop, April 2-3, The Hague.

Design-Based Research Collective 2003. Design-based research: An emerging paradigm for educational inquiry. Educational Researcher 32, no. 1: 5-8.

Edelson, D.C. 2002. Design research: What we learn when we engage in design. Journal of the Learning Sciences 11: 105-21.

Engeström, Y. 1987. Learning by expanding. Helsinki: Orienta-Konsultit.

Engeström, Y. 2008. From design experiments to formative interventions. Paper presented at the ISCAR 2008 Conference, September 8-13, San Diego, CA, USA.

Gravemeijer, K., and P. Cobb. 2006. Design research from a learning design perspective. In Educational design research, ed. J. van den Akker, K. Gravemeijer, S. McKenney, and N. Nieveen, 17-51. London: Routledge.

Hakkarainen, K. 2006. Scientific challenges of KP-Lab. Working paper, KP-Lab. University of Helsinki, Finland.

Hakkarainen, K. 2008. Features of trialogical learning: An introduction of research and development of Knowledge-Practices Laboratory. Working paper, KP-Lab. University of Helsinki, Finland.

Hakkarainen, K., T. Palonen, S. Paavola, and E. Lehtinen. 2004. Communities of networked expertise: Professional and educational perspectives. Amsterdam: Elsevier.

Hevner, A.R. 2007. A three cycle view of design science research. Scandinavian Journal of Information Systems 19, no. 2: 87-92.

Kali, Y. 2006. Collaborative knowledge building using a design principles database. International Journal of Computer-Supported Collaborative Learning 1, no. 2: $187-201$.

Kali, Y., R. Levin-Peled, and Y.J. Dori. 2009. The role of design-principles in designing courses that promote collaborative learning in higher-education. Computers in Human Behavior 25: 1067-78.

Kaptelinin, V., and R. Miettinen. 2005. Perspectives on the object of activity. Mind, Culture, and Activity 12, no. 1: 1-3.

Kaptelinin, V., B.A. Nardi, and C. Macaulay. 1999. Methods \& tools: The activity checklist: A tool for representing the "space" of context. Interactions 6, no. 4: 27-39.

Karlgren, K., A. Dahlström, K. Lonka, and S. Ponzer. 2007. A new educational annotation tool for supporting medical teams to improve their teamwork and communication. Paper presented at the ICEM/ILE 2007 - The International Council for Educational Media. September 20-22, Nicosia, Cyprus.

Knorr-Cetina, K. 2001. Objectual practice. In The practice turn in contemporary theory, ed. T.R. Schatzki, K. Knorr Cetina, and E. von Savigny, 175-88. London: Routledge.

KP-Lab. 2006a. Recommendations for design principles of trialogical technologies. Project deliverable D3.1, August. University of Oslo, Norway.

KP-Lab. 2006b. Scenarios and user requirements for KP-Labs in education. Project deliverable D8.1, August. FH OÖ Forschungs und Entwicklungs GmbH, Austria.

KP-Lab. 2007a. Summary of research on KP-Lab courses and technology in education. Research designs, pedagogical models, use of tools, and results of the first KP-Lab studies. Project deliverable D8.2, November. University of Helsinki, Finland; University of Utrecht, The Netherlands.

KP-Lab. 2007b. A collective case library about pedagogical models and related practices, v. 2. Project deliverable D9.2, November. Hebrew University of Jerusalem, Israel; University of Utrecht, The Netherlands.

KP-Lab. 2009a. Driving objectives and high-level requirements for KP-Lab technologies. Project deliverable D2.4, August. FH OÖ Forschungs und Entwicklungs GmbH, Austria; INPT, France. 
KP-Lab. 2009b. Summary of research on knowledge practices in education supported by KP-Lab technology. An appendix. Project deliverable D8.3, September. University of Helsinki, Finland; University of Utrecht, The Netherlands.

KP-Lab. 2010. Report on empirical research. Project deliverable DIV.6, March. University of Helsinki, Finland.

Lakkala, M., S. Paavola, K. Kosonen, H. Muukkonen, M. Bauters, and H. Markkanen. 2009. Main functionalities of the knowledge practices environment (KPE) affording knowledge creation practices in education. In Computer supported collaborative learning practices: CSCL2009 Conference Proceedings, ed. C. O'Malley, D. Suthers, P. Reimann, and A. Dimitracopoulou, 297-306. Rhodes: International Society of the Learning Sciences.

Lakkala, L., L. Ilomäki, K. Kosonen, S. Paavola, and H. Muukkonen. 2010. Exploring the applicability of trialogical design principles for examining knowledge practices in education. In Collaborative knowledge creation: Practices, tools and concepts, ed. A. Morch, A. Moen, and S. Paavola, chapter 10. http://www.knowledgepractices.info/wiki/index. php?title=Handbook_on_Trialogical_Learning.

Löwy, I. 1992. The strength of loose concepts - boundary concepts, Federative experimental strategies and disciplinary growth: The case of immunology. History of Science 30, no. 4: 371-96.

Mahemoff, M.J., and L.J. Johnston. 1998. Principles for a usability-oriented pattern language. Paper presented at the OZCHI '98, November 30-December 4, Adelaide, Australia.

McKenney, S., N. Nieveen, and J. Van den Akker. 2006. Design reserach from a curriculum perspective. In Educational design research, ed. J. van den Akker, K. Gravemeijer, S. McKenney, and N. Nieveen, 67-90. London: Routledge.

Muukkonen-van der Meer, H. 2011. Perspectives on knowledge creating inquiry in higher education. Doctoral diss., University of Helsinki, Institute of Behavioural Sciences. In Studies in Psychology, 75. Helsinki: Helsinki University Print.

Nonaka, I., and H. Takeuchi. 1995. The knowledge-creating company: How Japanese companies create the dynamics of innovation. New York: Oxford University Press.

Paavola, S., and K. Hakkarainen. 2005. The knowledge creation metaphor - An emergent epistemological approach to learning. Science \& Education 14: 535-57.

Paavola, S., and K. Hakkarainen. 2009. From meaning making to joint construction of knowledge practices and artefacts - A trialogical approach to CSCL. In Computer supported collaborative learning practices: CSCL2009 Conference Proceedings, ed. C. O’Malley, D. Suthers, P. Reimann, and A. Dimitracopoulou, 83-92. Rhodes: International Society of the Learning Sciences.

Paavola, S., L. Lipponen, and K. Hakkarainen. 2004. Models of innovative knowledge communities and three metaphors of learning. Review of Educational Research 74, no. 4: 557-76.

Rabardel, P., and G. Bourmaud. 2003. From computer to instrument system: A developmental perspective. Interacting with Computers 15, no. 5: 665-91.

Scardamalia, M. 2002. Collective cognitive responsibility for the advancement of knowledge. In Liberal education in a knowledge society, ed. B. Smith, 67-98. Chicago, IL: Open Court.

Sfard, A. 1998. On two metaphors for learning and the dangers of choosing just one. Educational Researcher 27: 4-13. 